BIOSFER: JURNAL PENDIDIKAN BIOLOGI (BIOSFERJPB)

2017, Volume 10 No 2, 42-48

ISSN: 08532451

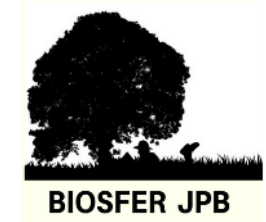

\title{
IMPLEMENTASI NILAI PENDIDIKAN KARAKTER PADA PEMBELAJARAN BIOLOGI DI SEKOLAH MENENGAH ATAS
}

\author{
Atira Elpariska Maya, Siti Huzaifah, Kodri Madang \\ Program Studi Pendidikan Biologi, Universitas Sriwijaya. \\ Jl. Raya Palembang-Prabumulih Indralaya, Ogan Ilir, Indonesia. Telp. 0711-580085 \\ E-mail: sitihuzaifahdjalil@gmail.com
}

\begin{abstract}
This research aims to describing the implementation of character education value in Biology lesson at Senior High School in Muara Enim Regency in respect to planning and implementation aspects of learning. The research subjects consisted of three Biology teachers determined by purposive sampling technique. Data collection techniques are used audiovisual materials and documents. Data were analyzed by transcription, coding and verifying data. the results of this research show that the implementation of character education value in Biology lesson on the aspect of planning and implementation consists of three things, namely 1) the values designed and implemented by Biology teachers consists of discipline, curiosity, and responsibility, 2) values designed but not implemented are discipline, creative value, curiosity value, and joy of reading, and 3) values that are not designed but implemented are discipline, hard work, reading, and responsibility. In general, Biology teachers are implemented character education value in learning through messages by using words. In addition, Biology teachers also have not utilized the learning materials at each meeting to develop the value of character education of the learners.
\end{abstract}

Keywords : Character Education, Biology Lesson

\section{PENDAHULUAN}

Pendidikan karakter didefinisikan sebagai pendidikan nilai, pendidikan budi pekerti, atau pendidikan moral (Jalal, dkk., 2011). Pendidikan karakter adalah suatu usaha menanamkan kebiasaan yang baik sehingga peserta didik mampu bersikap dan bertindak berdasarkan nilai-nilai yang telah menjadi kepribadiannya (Jalal, dkk., 2011). Selain itu, Lickona (2016) juga menyatakan bahwa pendidikan karakter merupakan usaha yang dilakukan dengan sengaja untuk mengembangkan kebajikan sehingga dapat mengarahkan pada kehidupan yang lebih baik. Pendidikan karakter mengembangkan 18 nilai yang secara khusus di identifikasi dari empat sumber yaitu (1) agama, (2) pancasila, (3) budaya, dan (4) tujuan pendidikan (Jalal, dkk., 2011). Nilai dalam pendidikan karakter tersebut memiliki relevansi dengan kurikulum yang diterapkan saat ini yaitu Kurikulum 2013 yang juga menekankan pada pembentukan sikap peserta didik (Rustantoro, 2014). Kurikulum 2013 bertujuan untuk meningkatkan mutu proses dan hasil pendidikan yang mengarah pada pembentukan budi pekerti dan akhlak mulia peserta didik secara utuh (Mulyasa, 2013).

Agar pendidikan karakter dapat diimplementasikan langsung pada peserta didik, maka salah satu strategi yang disarankan pemerintah adalah mengintegrasikan pendidikan 
karakter melalui semua mata pelajaran (Khusniati, 2012). Guru harus membimbing peserta didik agar tidak hanya dapat menangkap pesan dari apa yang mereka pelajari, namun peserta didik juga mampu menerapkan pesan dari setiap teori yang mereka pelajari (Setyaningrum dan Husamah, 2011). Saat ini, implementasi pendidikan karakter oleh guru Biologi masih beragam. Hasil penelitian Chastanti (2014) menunjukkan bahwa guru Biologi belum sepenuhnya mengimplementasikan nilai pendidikan karakter pada pembelajaran, sedangkan hasil penelitian Puji dkk. (2016) menunjukkan guru Biologi sudah mengimplementasikan nilai pendidikan karakter baik dari aspek perencanaan dan pelaksanaan pembelajaran.

Guru harus menyusun rencana pelaksanaan pembelajaran yang mengandung muatan karakter di dalamnya, Selain itu, pada aspek pelaksanaannya guru juga menyisipkan nilainilai pendidikan karakter pada proses pembelajaran (Chastanti, 2014). Guru dapat mengimplementasikan pendidikan karakter pada pembelajaran Biologi melalui beberapa cara. Menurut Yudianto (2015), guru Biologi dapat mengimplementasikan pendidikan karakter melalui materi pembelajaran Biologi yang dapat dijadikan perumpamaan atau analogi untuk peserta didik. Selain itu, menurut Khan (2010), pendidikan karakter dapat juga diimplementasikan dengan public speaking melalui komunikasi efektif yaitu suatu cara menyampaikan pesan untuk mencapai tujuan yang diinginkan.

Berdasarkan studi pendahuluan, beberapa guru Biologi SMA/SMK di Kabupaten Muara Enim telah mengimplementasikan pendidikan karakter pada pembelajaran. Hasil wawancara dengan pengawas guru SMA/SMK di Kabupaten Muara Enim, guru Biologi SMA Negeri di Kabupaten Muara Enim sudah konsisten mengimplementasikan pendidikan karakter pada pembelajaran dibandingkan dengan guru Biologi di SMA Swasta dan SMK Negeri serta Swasta (Ruminarsih, 2016; Komunikasi Pribadi). Namun demikian, hanya guru di 5 SMA Negeri yang mengimplementasikan pendidikan karakter secara konsisten meskipun Kabupaten Muara Enim memiliki 20 SMA Negeri yang terdiri atas 38 guru Biologi (Ruminarsih, 2016; Komunikasi Pribadi). Ditambahkan oleh pengawas guru SMA/SMK di Kabupaten Muara Enim, terdapat 5 SMA Negeri dengan 17 guru Biologi yang mengimplementasikan pendidikan karakter secara konsisten. Triatmanto (2010) menyatakan bahwa hasil dari pendidikan karakter tidak akan didapat secara instan. Oleh karena itu, konsistensi dalam mengimplementasikan pendidikan karakter sangat penting. Berdasarkan latar belakang tersebut, peneliti tertarik untuk mendapatkan informasi mengenai implementasi nilai pendidikan pendidikan karakter oleh guru Biologi SMA Negeri di Kabupaten Muara Enim.

\section{METODE PENELITIAN}

Penelitian ini merupakan penelitian kualitatif. Penelitian ini dilaksanakan di dua Sekolah Menengah Atas (SMA) yang berbeda di Kabupaten Muara Enim. Pengambilan data penelitian dilaksanakan pada tanggal 23 Januari 2017 - 01 Maret 2017. Subjek penelitian terdiri atas tiga guru Biologi (Guru B1, guru B2, dan guru B3) yang ditentukan dengan teknik purposive sampling. Jenis data yang dibutuhkan terdiri atas 1) Rencana Pelaksanaan Pembelajaran (RPP) yang dipergunakan saat pembelajaran, 2) transkrip hasil rekaman video subjek penelitian, dan 3) video pembelajaran subjek penelitian di kelas. Teknik pengumpulan data menggunakan materi audiovisual dan dokumen. Data dianalisis 
dengan transkripsi, pengkodean dan verifikasi data (Creswell, 2012). Validitas dan reliabilitas menggunakan dua cara yaitu 1) pengecekan anggota dan 2) validasi antara ahli (Koefisien Kappa). Lalu, hasil analisis data dijabarkan secara deskriptif.

\section{HASIL DAN PEMBAHASAN}

Data hasil penelitian mengenai implementasi nilai pendidikan karakter oleh ketiga guru SMA Negeri di Kabupaten Muara Enim dalam pembelajaran Biologi dari aspek pelaksanaan dikumpulkan dengan alat perekam video sebanyak tiga kali pertemuan yang kemudian ditranskripsi. Hasil analisis nilai pendidikan karakter yang diterapkan oleh guru Biologi telah divalidasi dua ahli dari FKIP Unsri menggunakan Koefisien Kappa. Data hasil penelitian mengenai nilai implementasi pendidikan karakter oleh ketiga guru Biologi dalam pembelajaran Biologi dari aspek perencanaan diperoleh dari Rencana Pelaksanaan Pembelajaran (RPP). Implementasi nilai pendidikan karakter oleh guru Biologi ditunjukkan pada Tabel 1 sebagai berikut.

Tabel 1. Implementasi pendidikan karakter oleh ketiga subjek penelitian.

\begin{tabular}{llllllllll}
\hline \multirow{2}{*}{ Jenis Nilai } & \multicolumn{3}{c}{$\mathrm{P} 1$} & \multicolumn{1}{c}{$\mathrm{P} 2$} & $\mathrm{P}$ \\
\cline { 2 - 10 } & $\mathrm{B} 1$ & $\mathrm{~B} 2$ & $\mathrm{~B} 3$ & $\mathrm{~B} 1$ & $\mathrm{~B} 2$ & $\mathrm{~B} 3$ & $\mathrm{~B} 1$ & $\mathrm{~B} 2$ & $\mathrm{~B} 3$ \\
\hline Disiplin & $\mathrm{P}$ & $\mathrm{R}$ & $\mathrm{R}$ & $\mathrm{Q}$ & $\mathrm{P}$ & - & $\mathrm{Q}$ & $\mathrm{P}$ & - \\
Kerja Keras & $\mathrm{R}$ & - & $\mathrm{R}$ & $\mathrm{R}$ & $\mathrm{R}$ & $\mathrm{R}$ & $\mathrm{R}$ & $\mathrm{R}$ & $\mathrm{R}$ \\
Kreatif & - & - & - & - & - & - & - & - & $\mathrm{Q}$ \\
Rasa Ingin Tahu & $\mathrm{P}$ & $\mathrm{Q}$ & $\mathrm{Q}$ & $\mathrm{P}$ & $\mathrm{Q}$ & $\mathrm{P}$ & $\mathrm{P}$ & $\mathrm{P}$ & $\mathrm{P}$ \\
Gemar Membaca & $\mathrm{R}$ & - & $\mathrm{P}$ & $\mathrm{R}$ & - & $\mathrm{P}$ & - & - & $\mathrm{Q}$ \\
Tanggung Jawab & $\mathrm{P}$ & $\mathrm{P}$ & $\mathrm{P}$ & $\mathrm{P}$ & $\mathrm{P}$ & $\mathrm{P}$ & $\mathrm{P}$ & $\mathrm{P}$ & $\mathrm{R}$ \\
\hline
\end{tabular}

\section{Keterangan :}

$\begin{array}{lll}\text { P1 } & \text { : Pertemuan ke 1 } & \text { P3 : Pertemuan ke } 3 \\ \text { B1 } & \text { : Subjek Penelitian 1/Guru 1 } & \\ \text { B2 } & \text { : Subjek Penelitian 1/Guru 2 } \\ \text { B3 } & \text { : Subjek Penelitian /Guru 3 } \\ \text { P } & \text { : Nilai yang dirancang dan dilaksanakan oleh guru } \\ \text { Q } & \text { : Nilai yang dirancang dan tidak dilaksanakan oleh guru } \\ \text { R } & \text { : Nilai yang tidak dirancang dan dilaksanakan oleh guru }\end{array}$

Implementasi nilai pendidikan karakter pada pembelajaran Biologi penelitian ini adalah pelaksanaan pendidikan karakter yang terintegrasi pada pembelajaran Biologi dalam bentuk nilai-nilai oleh guru Biologi, yang dilihat dari aspek perencanaan dan pelaksanaan pembelajaran. Implementasi pendidikan karakter pada pembelajaran Biologi oleh guru B1, guru B2, dan guru B3 terdiri atas 3 pembahasan yaitu: 1) nilai yang dirancang dan dilaksanakan oleh guru, 2) nilai yang dirancang dan tidak dilaksanakan oleh guru, dan 3) nilai yang tidak dirancang dan dilaksanakan oleh guru.

Guru B1, guru B2, dan guru B3 telah mengimplementasikan pendidikan karakter dengan membuat rancangan nilai pendidikan karakter yang ditulis dalam Rencana Pelaksanaan Pembelajaran (RPP) dan melaksanakan nilai yang dirancang tersebut dalam kegiatan pembelajaran. Sejalan dengan Marzuki (2012) bahwa guru harus menganalisis nilai pendidikan karakter yang akan dituliskan pada Rencana Pelaksanaan Pembelajaran (RPP) kemudian melaksanakan nilai yang sudah dirancang sebelumnya. 
Berdasarkan data yang didapat, guru B1 merancang dan melaksanakan nilai disiplin. Pada penelitian ini, guru B1 dan guru B2 melaksanakan nilai disiplin dengan membiasakan peserta didik mematuhi aturan dalam pembelajaran seperti mengingatkan peserta didik untuk tidak mengobrol pada saat pembelajaran berlangsung dan menutup buku pada saat kegiatan evaluasi pembelajaran. Lain halnya dengan guru B3 yang melaksanakan nilai disiplin dengan membiasakan peserta didik hadir dan tepat pada waktunya. Peserta didik guru B3 pada saat itu datang ke kelas terlambat. Apa yang dilakukan oleh guru B1, guru B2, dan guru B3 sejalan dengan pendapat Lickona (2014) bahwa hal yang dapat dilakukan oleh guru untuk mempraktekkan disiplin yaitu dengan cara yang membuat peserta didik menghargai tujuan dari suatu peraturan dan bersedia memperbaiki sikap yang salah.

Pada penelitian ini, guru B1, guru B2, dan guru B3 untuk menerapkan rasa ingin tahu selalu memberikan kesempatan kepada peserta didik untuk mengajukan pertanyaan tentang materi pelajaran. Menurut Philips (2014), memberikan kesempatan bertanya pada peserta didik dapat menumbuhkan rasa ingin tahu peserta didik yang diawali dengan timbulnya rasa penasaran dalam diri peserta didik. Dengan adanya rasa penasaran tersebut, maka peserta didik terpacu membuat pertanyaan yang lebih mendalam (Nurfauziyah, dkk., 2015). Selain memberikan kesempatan kepada peserta didik untuk mengajukan pertanyaan, guru B3 pada pertemuan ke 1 meminta peserta didiknya agar berupaya mencari informasi dari berbagai sumber belajar tentang konsep/masalah yang dipelajari. Sumber belajar yang disarankan oleh guru B3 yaitu lingkungan sekitar kelas, buku teks serta internet.

Nilai yang dirancang dan dilaksanakan oleh ketiga guru Biologi adalah gemar membaca. Berdasarkan hasil penelitian, nilai gemar membaca hanya dirancang dan dilaksanakan oleh guru B3 pada pertemuan ke 1 dan 2. Guru B3 selalu mengarahkan peserta didiknya untuk membuka dan membaca buku yang mereka miliki, baik dengan cara meminta langsung peserta didiknya untuk membuka buku atau melalui sindiran halus agar buku pelajarannya dibuka.

Nilai tanggung jawab merupakan salah satu nilai yang selalu dirancang dan dilaksanakan oleh guru B1, guru B2, dan guru B3. Berdasarkan data guru B1, B2, dan B3 selalu meminta peserta didik melaksanakan tugas yang diberikan. Ketiga guru Biologi tersebut sering meminta peserta didik untuk menyelesaikan soal-soal dari Lembar Kerja Peserta Didik (LKPD) dan meminta peserta didik untuk menjelaskan atau mempresentasikan jawabannya. Sejalan dengan Lickona (2014), guru diberi hak untuk meminta peserta didik mengikuti pengarahan, mengerjakan tugas yang dibuat olehnya.

Nilai yang dirancang namun tidak dilaksanakan oleh guru B1, guru B2, dan guru B3 adalah nilai disiplin, nilai kreatif, nilai rasa ingin tahu, dan nilai gemar membaca. Menurut hasil penelitian Zendrato (2016), guru mengambil keputusan untuk tidak melaksanakan beberapa kegiatan yang sudah dirancang dalam Rencana Pelaksanaan Pembelajaran (RPP) karena respon peserta didik, situasi kelas atau berfokus pada pencapaian tujuan pembelajaran dan penyelesaian materi.

Berdasarkan data guru B1, B2, dan B3 ternyata melaksanakan nilai pendidikan karakter yang tidak dirancang terlebih dahulu dalam Rencana Pelaksanaan Pembelajaran (RPP). Adapun nilai yang tidak dirancang namun dilaksanakan oleh ketiga guru Biologi adalah disiplin, kerja keras, gemar membaca, dan tanggung jawab. Menurut Zendrato (2016), kegiatan yang tidak ditulis dalam Rencana Pelaksanaan Pembelajaran (RPP) tetapi 
muncul di dalam pelaksanaan pembelajaran di kelas dapat terjadi ketika guru melihat kebutuhan peserta didik pada saat itu.

Nilai disiplin tidak dirancang namun dilaksanakan oleh guru B2 dan guru B3 pada pertemuan ke 1. Guru B2 selalu mengingatkan peserta didiknya untuk mematuhi aturan dalam pembelajaran seperti mengangkat tangan sebelum menjawab pertanyaan dari guru sehingga guru dapat menunjuk satu orang untuk menjawab. Lain halnya dengan guru B3, pada pertemuan ke 1 didapati seorang siswa yang tidak hadir dengan keterangan alfa. Selain nilai disiplin, nilai kerja keras juga merupakan nilai yang tidak dirancang dan dilaksanakan oleh guru B1, guru B2, dan guru B3. Berdasarkan hasil penelitian, guru B1 menerapkan nilai gemar membaca dengan selalu meminta peserta didik untuk membuka dan membaca buku pelajaran yang mereka miliki. Nilai terakhir yang tidak dirancang namun dilaksanakan oleh guru adalah nilai tanggung jawab. Pada penelitian ini, nilai tanggung jawab yang tidak dirancang namun dilaksanakan oleh guru hanya dilakukan oleh guru B3 pada pertemuan ke 3. Nilai tanggung jawab dilaksanakan dengan memberi hukuman kepada ketua kelas karena tidak mengingatkan teman-temannya untuk pindah kelas sehingga menyebabkan berkurangnya jam pelajaran.

Pada penelitian ini, secara umum guru B1, B2, dan B3 mengimplementasikan nilai pendidikan karakter pada pembelajaran Biologi melalui pesan yang menggunakan katakata, baik dengan mengingatkan atau meminta peserta didik melakukan sesuatu agar nilai pendidikan karakter tersebut dapat dibiasakan pada diri peserta didik. Menurut Khan (2010), salah satu strategi pendidikan karakter yang dapat diterapkan adalah public speaking melalui komunikasi efektif yaitu suatu cara menyampaikan pesan untuk mencapai tujuan yang diinginkan. Penggunaan kata-kata secara berulang dilakukan oleh guru untuk membiasakan nilai pendidikan karakter pada peserta didik walaupun tidak semua guru melakukannya.

Penelitian ini dilakukan pada tiga materi pembelajaran yang sama dilaksanakan oleh masing-masing guru Biologi. Pada pertemuan ke 1, ketiga guru sama-sama mengajarkan materi pembelajaran mengenai Spermatophyta. Pada pertemuan ke 2, ketiga guru Biologi mengajarkan materi pembelajaran mengenai Porifera dan Coelenterata. Pertemuan ke 3, ketiga guru Biologi mengajarkan materi pembelajaran mengenai dunia cacing (Platyhelmintes, Nemathelmintes, dan Annelida). Guru B1, B2, dan B3 belum memanfaatkan materi pembelajaran pada masing-masing pertemuan untuk mengembangkan nilai pendidikan karakter peserta didik. Didukung dari hasil wawancara pemahaman guru Biologi mengenai implementasi pendidikan karakter, guru B1, B2, dan B3 tidak menjelaskan bahwa pada tahap perencanaan guru dapat menyiapkan bahan ajar dengan merevisi atau menambah nilai-nilai kedalam pembahasan materi yang akan disampaikan. Padahal, pendidikan karakter dapat diintegrasikan dalam pembelajaran Biologi melalui materi pembelajaran sebagai model-model Biologi yang dapat dijadikan amtsal untuk pembelajaran peserta didik (Yudianto, 2015). Hal ini juga didukung oleh Lickona (2016) bahwa guru dapat mengajarkan akademik dan karakter secara bersamaan.

\section{KESIMPULAN}

Implementasi nilai pendidikan karakter oleh guru Biologi SMA Negeri di Kabupaten Muara Enim pada aspek perencanaan dan pelaksanaan pembelajaran. Nilai yang 
dirancang dan dilaksanakan oleh guru Biologi terdiri atas disiplin, rasa ingin tahu, gemar membaca, dan tanggung jawab. Nilai yang dirancang namun tidak dilaksanakan adalah disiplin, nilai kreatif, nilai rasa ingin tahu, dan nilai gemar membaca. Nilai yang tidak dirancang namun dilaksanakan adalah disiplin, kerja keras, gemar membaca, dan tanggung jawab. Secara umum, guru Biologi melaksanakan pendidikan karakter pada pembelajaran melalui pesan yang menggunakan kata-kata. Selain itu, guru Biologi juga belum memanfaatkan materi pembelajaran pada masing-masing pertemuan untuk mengembangkan nilai pendidikan karakter peserta didik.

\section{DAFTAR PUSTAKA}

Chastanti, I. (2014). Analisis Implementasi Pendidikan Karakter pada Pembelajaran Biologi di SMA Negeri Kabupaten Labuhanbatu Utara. Tesis. Medan: Universitas Negeri Medan.

Creswell, J. W. (2012). Educational Research: Planning, Conducting, and Evaluating Quantitative and Qualitative Research ( $4^{\text {th }}$ ed). Boston: Pearson Education, Inc.

Jalal, F., Anas, Z., Hamka, M., Somantrie, H., Suhardi \& Sumiyati. (2011). Panduan Pelaksanaan Pendidikan Karakter. Jakarta: Pusat Kurikulum dan Perbukuan, Penelitian dan Pengembangan, Kementerian Pendidikan Nasional.

Khan, Y. (2010). Pendidikan Karakter Berbasis Potensi Diri. Yogyakarta: Pelangi Publishing.

Khusniati, M. (2012). Pendidikan Karakter Melalui Pembelajaran IPA. Jurnal Pendidikan IPA Indonesia. 1 (2): 204-210.

Lickona, T. (2016). Character Matters (Persoalan Karakter): Bagaimana Membantu Anak Mengembangkan Penilaian yang Baik, Integritas, dan Kebajikan Penting Lainnya. Diterjemahkan oleh Juma Abdu \& Jean Antunes. Jakarta: Bumi Aksara.

Lickona, T. (2014). Pendidikan Karakter: Panduan Lengkap Mendidik Siswa Menjadi Pintar dan Baik. Diterjemahkan oleh Lita. Bandung: Nusa Media.

Marzuki. (2012). Pengintegrasian Pendidikan Karakter dalam Pembelajaran di Sekolah. Jurnal Pendidikan Karakter. 2 (1): 33-44.

Mulyasa. (2013). Pengembangan dan Implementasi Kurikulum 2013. Bandung: Remaja Rosdakarya.

Nurfauziyah, S., Marjono \& Bowo S. (2015). Penerapan Guided Inquiry untuk Meningkatkan Rasa Ingin Tahu Siswa pada Pembelajaran Biologi di Kelas XI IPA SMA Al Muayyad Surakarta Tahun Pelajaran 2014/2015. Disajikan dalam Seminar Nasional XII Pendidikan Biologi, FKIP Universitas Negeri Semarang. 
Philips, R. (2014). Space for Curiosity. Journal of Progress in Human Geography. 38(4): 493-512.

Rustantoro, T. (2014). Kurikulum 2013 Membangun Karakter. Jawa Tengah: Widyaiswara LPMP.

Setyaningrum, Y. \& Husamah. (2011). Optimalisasi Penerapan Pendidikan Karakter di Sekolah Menengah Berbasis Keterampilan Proses: Sebuah Perspektif Guru IPABiologi. Jurnal Penelitian dan Pemikiran Pendidikan. 1 (1) : 69-81.

Triatmanto. (2010). Tantangan Implementasi Pendidikan Karakter di Sekolah. Cakrawala Pendidikan. 1 (3): 187-203.

Yudianto, S. A. (2015). Implementasi Pendidikan Karakter/Nilai dalam Pembelajaran Biologi. Disajikan dalam Seminar Nasional Pendidikan Biologi-IPA, 14 November 2015, FKIP Universitas Sriwijaya.

Zendrato, J. 2016. Tingkat Penerapan Rencana Pelaksanaan Pembelajaran dalam Pelaksanaan Pembelajaran di Kelas Studi Kasus di SMA Dian Harapan Jakarta. Scholaria. 6 (2): 58-73. 